\title{
Expression of Brca1 is associated with terminal differentiation of ectodermally and mesodermally derived tissues in mice
}

\author{
Timothy F. Lane, ${ }^{1,4}$ Chuxia Deng, ${ }^{1,3}$ Ari Elson, ${ }^{1}$ Myung S. Lyu, ${ }^{2}$ Christine A. Kozak, ${ }^{2}$ \\ and Philip Leder ${ }^{1}$ \\ ${ }^{1}$ Department of Genetics, Harvard Medical School and Howard Hughes Medical Institute (HHMI), Boston, Massachusetts \\ 02115 USA; $^{2}$ National Institute for Allergy and Infectious Diseases, National Institutes of Health, Bethesda, Maryland \\ 20892 USA
}

\begin{abstract}
We have isolated genomic and cDNA clones of Brca1, a mouse homolog of the recently cloned breast cancer-associated gene, BRCA1. Brca1 encodes an 1812-amino-acid protein with a conserved zinc finger domain and significant homology to the human protein. Brca1 maps to Chromosome 11 within a region of conserved synteny with human chromosome 17, consistent with the mapping of the human gene to $17 \mathrm{q} 21$. Brca1 transcripts are expressed in a variety of cultured cells but reveal a specific and dynamic expression pattern during embryonic development. For example, expression is observed first in the otic vesicle of embryonic day 9.5 (E9.5) embryos. This expression diminishes and is replaced by expression in the neuroectoderm at E10.5. By E11-12.5, higher levels are observed in differentiating keratinocytes and in whisker pad primordia. Transcripts also become evident in epithelial cells of the E14-17 kidney. Brca1 expression occurs in differentiating epithelial cells of several adult organs as well, suggesting a general role in the functional maturation of these tissues. Consistent with this, Brca1 transcripts are expressed in both alveolar and ductal epithelial cells of the mammary gland. During pregnancy, there is a large increase in Brca1 mRNA in mammary epithelial cells, an increase that parallels their functional differentiation. Because high rates of breast cancer are associated with loss of BRCA1 in humans, it is possible that this gene provides an important growth regulatory function in mammary epithelial cells. In addition, increased transcription of mammary Brca1 during pregnancy might contribute, in part, to the reduced cancer risk associated with exposure to pregnancy and lactation.
\end{abstract}

[Key Words: Brca1 expression; mouse homolog; embryomic development; terminal differentiation; transcription; mammary gland; Ring finger]

Received August 10, 1995; revised version accepted September 14, 1995.

Roughly $5 \%$ of the breast cancers diagnosed in North America and Europe are attributed to family history. ${ }^{1}$ One candidate gene, referred to as $B R C A 1$, is thought responsible for $45 \%$ of these hereditary cancers, and $\mathrm{mu}$ tant alleles confer a lifetime risk approaching 85\% (Easton et al. 1993, 1995). A variable risk of ovarian cancer is also present and approaches $60 \%$ in some kindreds. Positional cloning led to the identification of the human BRCA1 gene in 1994 (Miki et al. 1994). Conceptual translation of cDNAs from this locus revealed a large C3HC4-type zinc finger protein expressed in the breast and ovary, as well as in a variety of adult tissues that appear unaffected by disease. Germ-line mutations have been identified in $>80$ afflicted families /Castilla et al. 1994; Friedman et al. 1994; Futreal et al. 1994). Disease

\footnotetext{
${ }^{3}$ Present address: Laboratory of Biochemistry and Metabolism, National Institutes of Health, Bethesda, Maryland 20892 USA.

${ }^{4}$ Corresponding author.
}

follows the loss of the wild-type allele, a result that classifies $B R C A 1$ as a tumor suppressor gene. Whereas $B R C A 1$ mutations do not contribute greatly to nonfamilial late-onset breast cancers, somatic mutations have been characterized in a number of sporadic cases of ovarian cancer (Hosking et al. 1995; Merajver et al. 1995). Both inherited and somatic mutations result in truncation of the gene product, alterations of the amino acid sequence, or reduced transcription of the BRCA1 mRNA.

Mutations in tumor suppressor genes typically act recessively, and result, by diverse mechanisms, in loss of cellular growth control (p53, Rb protein, APC, DCC, NF1), or in reduced fidelity of DNA repair (p53, MSH2). The p53 gene product is involved in both cell cycle and DNArepair activities. C3HC4-type zinc finger proteins (also known as Ring finger or A box proteins) show transactivation activity for a number of viral and cellular genes (Patarca et al. 1988) and have been implicated in 
DNA repair (Jones et al. 1988). However, unlike other zinc finger motifs, $\mathrm{C} 3 \mathrm{HC} 4$-finger proteins might not have direct DNA-binding activity and their mode of action is unknown (Freemont 1993). Recent antisense experiments indicate that inhibition of $B R C A 1$ transcription leads to elevated proliferation in certain breast cell lines (Thompson et al. 1995). Thus, it seems reasonable to predict that $B R C A 1$ will be involved, at least in part, in cell cycle control.

Because little is known about the role of $B R C A 1$ in development and cellular regulation, we set out to define its role in mice, a species where the contribution of specific genes to aspects of development and disease are studied more easily. To establish its structure and pattern of expression, and to test the hypothesis that loss of expression might play a role in mouse breast cancer, we have cloned a mouse homologue that we term Brca1. We find that Brca1 encodes an 1812-amino-acid protein that has $58 \%$ amino acid identity with the human protein. The amino-terminal zinc finger domain is $100 \%$ identi$\mathrm{cal}$, as are smaller domains of unknown function. Brca1 is located on Chromosome 11, in a region of conserved synteny with human chromosome $17 \mathrm{q} 21$. Interestingly, Brca1 is expressed during the development of the neuroepithelium and of several epithelial organs, including the kidney, skin, and mammary gland. Significantly, Brca1 expression increased sharply during pregnancy-induced mammary gland development in a pattern consistent with its regulation by pregnancy-associated hormonal changes. Because sequence conservation is an indication of functional conservation, it would appear that study of conserved features between BRCA1 genes in diverse species will provide considerable insight into functional domains of this large tumor suppressor locus.

\section{Results}

\section{Characterization of Brcal structure}

A 752-bp fragment of Brca1 (Fig. 1, probe A) was amplified from mouse genomic DNA with primers derived from exon 11 of the human gene (Miki et al. 1994) and used to isolate clones from a mouse genomic library. One genomic clone was found to contain the complete sequence of an exon homologous to human exon 11 . Fragments from this sequence were used to isolate $B r c a 1$ clones from a mouse embryonic day 17 (E17) cDNA library. The longest cDNA clones terminated $\sim 15 \mathrm{bp}$ short of the expected ATG initiation site, and oligonucleotides from this region were used to isolate additional genomic clones that overlapped this region (Fig. 1; data not shown). Sequence analysis of the overlapping clones shown in Figure 1 revealed that $6515 \mathrm{bp}$ of $B r c a 1$ cDNA had been identified. An ATG triplet at the $5^{\prime}$ end of this sequence was followed by a 5437-bp open reading frame. A 1002-bp 3'-untranslated region contained an -AATAAA- polyadenylation signal that was followed by a long tract of adenosine residues. (The nucleotide sequence is available from GenBank under accession no. U36475.)

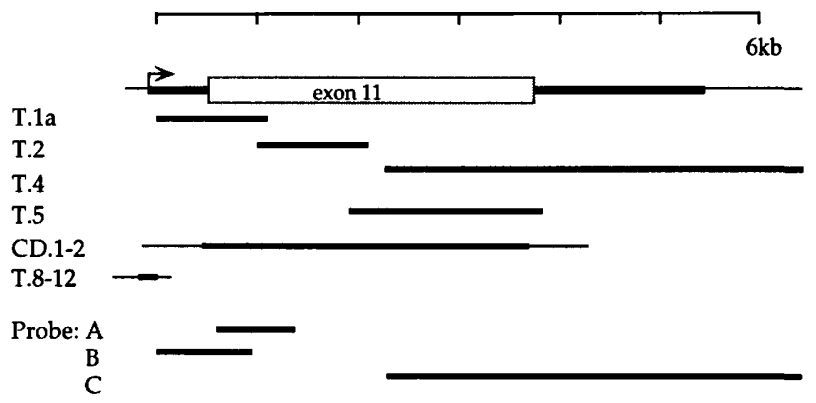

Figure 1. Map of Brca1 clones. Predicted structure of Brca1 mRNA based on the complete characterization of four independent cDNA clones (T.1-5) and partial characterization of two genomic fragments (CD.1-2 and T.8-12). The arrow indicates the location of the ATG codon predicted to be the start of translation. The location of exon 11 is indicated as an open rectangle, and the 5436-bp open reading frame by a thick line. Noncoding sequence are indicated by a thin line. The T.8-12 genomic fragment contained the sequence for exon 2 , which contains the start of translation. Exon 1, a noncoding exon identified in human cDNAs, has not been identified. The location of probes used for genomic mapping and mRNA expression studies are also included.

The mouse cDNA predicts an 1812-amino-acid protein similar in size and structure to the human $B R C A 1$ gene product (Fig. 2A). Brca1 is $100 \%$ identical to the human protein over a 49 -amino-acid region that includes the amino-terminal C3HC4-zinc-binding domain. The amino-terminal location is similar to the placement of homologous domains in rpt-1, a regulator of the IL-2 receptor (Patarca et al. 1988), RAD18, a DNA repair gene from yeast (Jones et al. 1988), ringl, a zinc-binding protein (Lovering et al. 1993), the human oncogenes ret, MEL18, and BMI-1 (Takahashi et al. 1988; Tagawa et al. 1990; Haupt et al. 1991; van Lohuizen et al. 1991), and others (Freemont 1993; Lovering et al. 1993).

Overall, Brca1 shares $58 \%$ amino acid identity with the predicted human protein. When conservative substitutions were included, homology increased to $73 \%$. Mouse and human $B R C A 1$ proteins also share similar charge and hydrophilic character. In particular, the amino terminus has several clusters of basic residues, whereas the middle and carboxyl terminus of the protein are generally acidic in character and contain a proportionally high number of serines (Fig. 2B). Whereas nothing is known about the subcellular distribution or phosphorylation state of $B R C A 1$, two conserved clusters of basic residues appear homologous to nuclear localization signals found in SV40 (Kalderon et al. 1984) (Fig. 2A). Several conserved serines are found in acidic environments similar to known sites of phosphorylation by casein kinase II and glycogen-synthase kinase 3 (Litchfield et al. 1990; Park et al. 1994).

\section{Organization and location of the Brcal gene}

Sequence analysis of genomic clones resulted in the characterization of the complete structure of exon 11 
Lane et al.

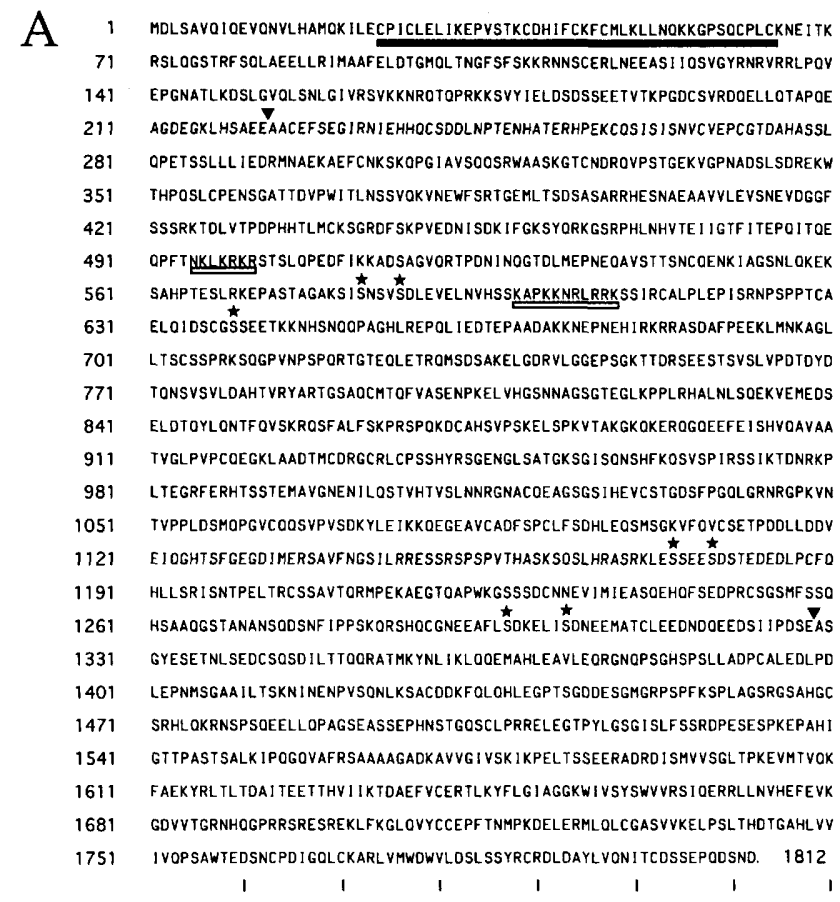

B

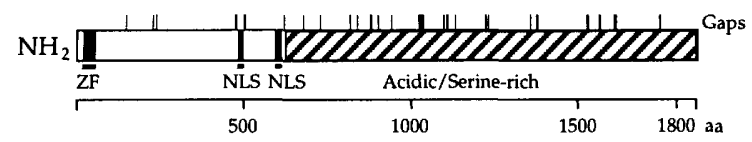

Figure 2. Mouse Brca1 encodes an 1812-amino-acid protein with an amino-terminal C3HC4-type zinc finger. $(A)$ Deduced amino acid sequence of Brcal is given in one-letter symbols. The amino acids predicted to comprise a C3HC4-type zinc finger are underlined. ( $)$ The boundaries of exon 11. Two conserved basic motifs similar to the SV40 nuclear localization signal (Kalderon et al. 1984) are shown with open underlines. The location of several conserved serines that lie within acidic environments are indicated by a star. The complete sequence of the derived Brca1 cDNA has been deposited in GenBank (accession no. U36475). (B) A bar diagram of the predicted Brca1 protein is shown with the location of the amino terminus $\left(\mathrm{NH}_{2}\right)$, the zinc-finger $(\mathrm{ZF})$, two potential nuclear localization signals (NLS), and a relatively acid- and serine-rich domain. Vertical lines above indicate the locations of gaps between the human (Miki et al. 1994) and mouse proteins. Gaps result in a net loss of 53 amino acids in the mouse sequence.

(clone CD.1-2) and the intron 1-exon 2 boundary (clone T.8-12) (Fig. 1; data not shown). The extensive similarity between the $5^{\prime}$ end of the mouse coding region with human exon 2 and the conserved structure of exon 11 indicate extensive similarity between human and mouse in the organization of the Brca1 locus.

The mouse Brca1 gene was mapped by Southern blot analysis of progeny from two multilocus crosses as described (Kozak et al. 1995) (Fig. 3). Linkage was detected with several markers on Chromosome 11, including Wnt 3 and Neu/Erbb2, which are also linked to the human BRCA1 locus (Lossie et al. 1994). This map location places $B r c a 1$ within a region of conserved synteny with human chromosome 17q21-22 and rat chromosome 10.

\section{Expression of Brcal mRNA in cell lines and embryos}

When probed with a $5^{\prime}$ cDNA fragment (Fig. 1; probe B), a single major $B r c a 1$ transcript was detected on Northern blots of poly $\mid \mathrm{A})^{+}$RNA prepared from a number of normal and transformed mouse cell lines (Fig. 4A). This major transcript migrated at $\sim 7.2 \mathrm{~kb}$ on $1 \%$ agarose-formaldehyde gels. This size is in reasonable agreement with the $6.5-\mathrm{kb}$ mouse cDNA sequence that has been characterized thus far, the difference accounted for by the presence of one or more untranslated exons lying $5^{\prime}$ of the start of translation and by the poly(A) tract at the $3^{\prime}$ end. Minor transcripts were also evident at $\sim 4.6$ and $5 \mathrm{~kb}$ (Fig. $4 \mathrm{~A}, \mathrm{~B}$, arrowheads).

Similar transcripts were identified in both normal and transformed mammary epithelial cells, as well as in primary tumors derived from the mammary and salivary glands of transgenic mice (Fig. 4A,B). In addition, a large number of nonepithelial tumors and cell lines also ex-

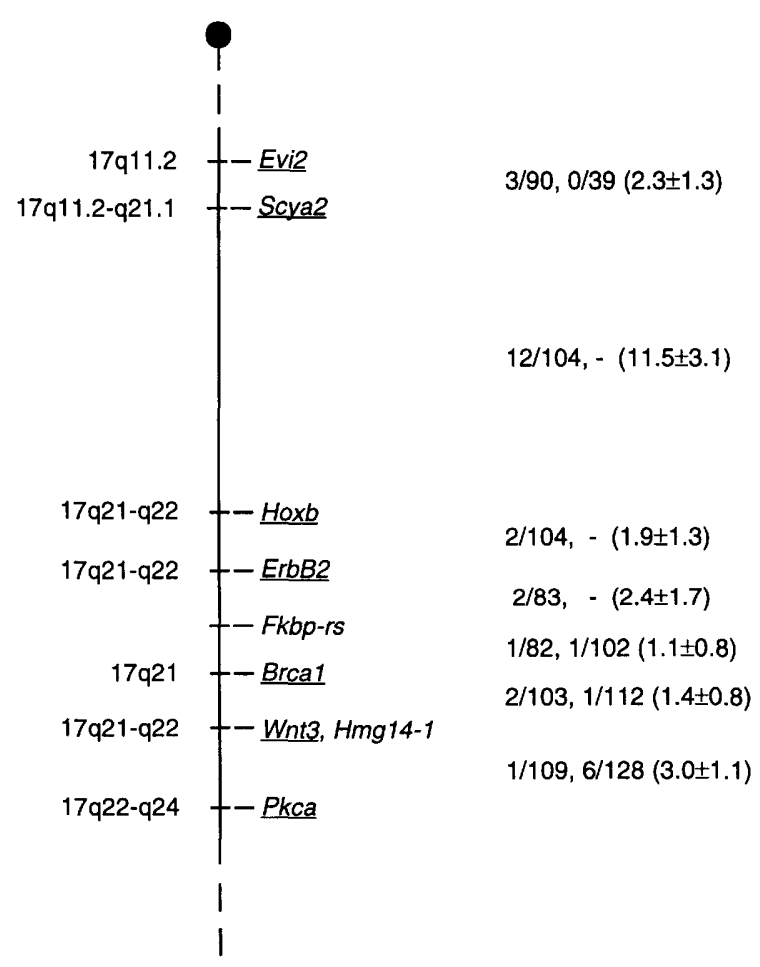

Figure 3. Brca1 is located on Chromosome 11. A diagram of Chromosome 11 is given with the relative positions of eight genes mapped previously to this region. (O) The centromere. Minimization of recombinant frequencies between Brca1 and these markers placed it centromeric to Wnt 3 and Hmg14-1 but distal to Erbb2 and Fkbp-rs. Recombination fractions for adjacent markers are given at right and were derived from analysis of the progeny of two multilocus crosses: The first fraction was derived from crosses carried out with $M$. spretus; the second fraction was from $M$. m. musculus. Numbers in parentheses represent the recombinational distances \pm S.E. and were calculated according to Green (1981). No double recombinants were identified within this interval in either cross. To the left of the map are human map locations for the underlined genes. The $M$. m. musculus cross was not typed for Hoxb and Erbb2. 


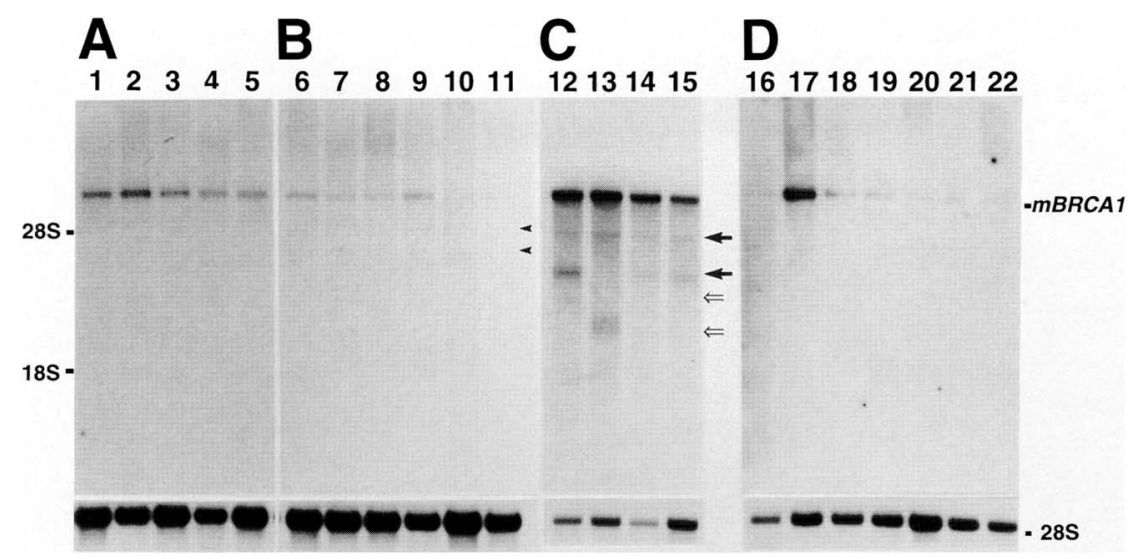

Figure 4. Expression of Brcal mRNA in cell lines, primary tumors, and embryonic brain. $\{A, B\} \mathrm{A} 7.2-\mathrm{kb}$ transcript is detected in a variety of cultured cells when probed with a 900-bp fragment from the $5^{\prime}$ end of the Brca1-coding region (Fig. 1, probe B). $(A)$ Mammary tumor cell lines: AC816, rastransformed (lane 1); M158, myc-transformed (lane 2); NK417, neu-transformed (lane 3). Nontransformed mammary cell lines: CL-S1 (lane 4); NMuMG (lane 5). $(B)$ Primary mammary tumors from transgenic mice over-expressing neu (lane 6), ras (lane 7), and myc (lanes 9 and 10). (Lane 8) Salivary gland tumor from a ras-transgenic mouse; (lane 11) NIH-3T3 cell line. Smaller transcripts are also identified (arrowheads). (C) Additional bands (arrows) are visible in blots probed with a 4-kb fragment from the middle and 3' end of the Brca1-coding region (Fig. 1, probe C). Mammary cell lines: SMF, neu-transformed (lane 12); 16MB9a, myc-transformed (lane 13); AC204, ras-transformed (lane 14); NMuMG, non-transformed (lane 15). Solid arrows indicate smaller transcripts identified in lanes 12, 14, and 15. Open arrows indicate those in lane 13. (D) Brca1 mRNA expression peaks in E12.5 head and is expressed in brain throughout development: E10.5 head (lane 16), E12.5 head (lane 17), E14.5 brain (lane 18), E16.5 brain (lane 19), E18.5 brain (lane 20), day 2 postpartum brain (lane 21), adult brain (lane 22). Timed Swiss-Webster embryos were prepared as described in the text. The adult brain tissue was from an 8 - to 10-week-old male FVB mouse. Transformed cell lines and tumors were derived from transgenic mouse lines overexpressing ras, myc, neu, or int2, as described in the text. All lanes contain $2 \mu \mathrm{g}$ of poly $(\mathrm{A})^{+}$RNA analyzed on $1 \%$ agarose/formaldehyde gels. Blots were exposed to x-ray film for 5 days. RNA loading was verified by reprobing blots with a fragment of the $28 \mathrm{~S}$ rRA and exposed for 2-8 hr.

pressed Brca1 mRNA (Table 1). Amplification of the 5' $250 \mathrm{bp}$ from several normal and transformed cell lines by RT-PCR failed to identify any major differences between Brca1 transcripts (not shown). Whereas many tumors and cell lines appeared to express relatively high levels of Brca1 transcript, one myc-based mammary tumor had significantly reduced levels (Fig. 4, lane 10). Whereas it has been suggested that reduced expression of Brca1 contributes to human breast disease (Thompson et al. 1995), it remains to be determined whether the reduction in $B R C A$ expression seen in this mammary tumor is linked to transformation.

Several fibroblast- and lymphoid-derived tumors also expressed Brca1, (Table 1), as did NIH-3T3 cells (Fig. 4, lane 11). Expression in these cells often seemed lower than in epithelial cell lines, but this was not always the case (Table 1).

When a probe corresponding to the middle and $3^{\prime}$ ends of the Brca1 cDNA was used (Fig. 1, probe C), smaller transcripts were observed (Fig. 4C). These smaller transcripts appear to vary between cell lines. One pattern of transcripts was observed in ras, neu, and normal mammary epithelial cell lines, whereas a fourth line derived from a myc overexpressing mouse gave two smaller transcripts (cf. transcripts identified by arrows in lanes 12, 14 , and 15 with those identified by open arrows in lane 13). These transcripts appear to lack exons $5^{\prime}$ of exon 11.

Northern blots of RNA from embryonic head [E10.5 post coitus (p.c.) and 12.5 p.c.] and brain (E14 p.c. through day 2 postnatal) show expression of Brca1 (Fig. 4D). Low levels of Brca1 transcripts were detected in embryonic heads of E10.5 embryos and increased dramatically in E12.5 embryonic head tissue (Fig. 4, lanes 16 and 17, respectively|. Brca1 mRNA was evident in isolated brain tissue of mice between E14.5 and postnatal day 2 (Fig. 4, lanes 18-21), very low levels of message were detected in adult brain (lane 22).

\section{In situ hybridization for Brcal expression in embryos}

To identify more precisely the cells in which Brca1 was expressed, we prepared staged embryos for in situ hybridization. Whole-mounted embryos displayed Brca1 mRNA in their otic vesicles at E9.5 (Fig. 5A). In E10.5 embryos, otic vesicle staining was diminished and tissues in the forebrain became distinctly positive (Fig. 5B). This expression was specific as neither sense nor irrelevant probes stained this region (Fig. $5 \mathrm{C}$; and data not shown). Although epithelial staining was eliminated by proteinase treatment of whole-mounted embryos, clear expression was evident in the neuroepithelium of sectioned embryos between E10.5 and E15.5 (Fig. 5D). Later in development, expression in the mesonephros (a precursor of the kidney) became evident (Fig. 5E). Sectioned embryos from E14.5 through E17.5 show that the expression was localized to tubular epithelial cells of the developing kidney [Fig. 5F, F(i)].

Localized expression in the skin of sectioned embryos was evident beginning at E10.5 (Fig. 6A). Intense hybridization in keratinocytes continued throughout embryonic development and was associated with both basal and suprabasal cells (Fig. 6B). Expression was reduced, but present, in adult skin (not shown). Expression in keratinocytes was most evident in dorsal skin and was weaker in the face and ventral body wall (Fig. 6C,E). Transcripts in facial skin of E13.5 embryos show a periodic pattern reminiscent of whisker follicle development (Fig. 6D). At E15.5, strong reactivity was identified in 
Table 1. Expression of Brcal $m R N A$ in cell lines and tumors

\begin{tabular}{|c|c|c|c|c|}
\hline & Status ${ }^{a}$ & Source $^{a}$ & Genotype $^{\mathrm{b}}$ & Expression \\
\hline \multicolumn{5}{|l|}{ Cell lines } \\
\hline NIH-3T3 & $\mathrm{N}$ & $\mathrm{E}$ & wt & + \\
\hline 1615 & $\mathbf{N}$ & M & wt & ++ \\
\hline 1636 & $\mathbf{N}$ & M & wt & ++ \\
\hline AC204 & $\mathrm{T}$ & $\mathrm{MA}$ & ras & +++ \\
\hline $\mathrm{AC} 236$ & $\mathrm{~T}$ & MA & ras & +++ \\
\hline AC816 & $\mathrm{T}$ & MA & ras & +++ \\
\hline SMF & $\mathrm{T}$ & MA & neu & +++ \\
\hline $16 \mathrm{mb} 9 \mathrm{a}$ & $\mathrm{T}$ & MA & myc & +++ \\
\hline NX1128 & $\mathrm{T}$ & MA & int2 & +++ \\
\hline HPI-2 & $\mathrm{H}$ & $\mathrm{M}$ & int2 & ++ \\
\hline $\mathrm{AC} 101$ & $\mathrm{~T}$ & $\mathrm{~F}$ & ras & +++ \\
\hline $\mathrm{AC} 280$ & $\mathrm{~T}$ & $\mathrm{~F}$ & ras & ++ \\
\hline AC139 & $\mathrm{T}$ & UF & ras & ++ \\
\hline \multicolumn{5}{|l|}{ Primary tumors } \\
\hline adenocarcinoma & & MA & neu & ++ \\
\hline adenocarcinoma & & MA & $m y c$ & ++ \\
\hline adenocarcinoma & & MA & $m y c$ & ++ \\
\hline adenocarcinoma & & MA & ras & ++ \\
\hline adenocarcinoma & & S & ras & ++ \\
\hline lymphoma ${ }^{c}$ & & Th & $m y c / p 53^{-1-}$ & ++ \\
\hline lymphoma ${ }^{c}$ & & $\mathrm{LN}$ & $m y c / p 53^{-1-}$ & ++ \\
\hline
\end{tabular}

Northern analysis of $2 \mu \mathrm{g}$ of poly $(\mathrm{A})^{+}$mRNA from subconfluent cultures with ${ }^{32}$ P-labeled probe B. Samples with a visible $7.2-\mathrm{kb}$ band after 1-day exposure were considered +++ , those with a band after 5 days were considered ++ , and those with a faint band after 5 days were considered + .

${ }^{a}(\mathrm{~N})$ Normal; $(\mathrm{H})$ hyperplasia; $(\mathrm{T})$ transformed; (wt) wild type; (E) embryo; (M) mammary gland; (MA) mammary adenocarcinoma; $(\mathrm{F})$ fibrosarcoma; (UF) uterine fibrosarcoma; (S) salivary gland; (Th) thymus; (LN) lymph node.

${ }^{b}$ Cell lines were derived from mice either wild type $(\mathrm{wt})$ or overexpressing ras, myc, neu, or int2, as described in the text.

${ }^{c}$ Lymphomas arose in mice overexpressing c-myc and lacking functional p53.

whisker pads, with only moderate expression in the overlying epidermis (Fig. 6E). The reason for the locally modulated levels of Brca1 in the skin is not known but could result from well-known differences in the timing of epidermal differentiation or in local differences in the expression of particular keratinocyte markers (Vassar and Fuchs 1991).

\section{Expression of Brcal in adult tissues and differentiation of the mammary gland}

Expression of Brca1 mRNA was evident in several adult tissues (Table 2). Highest levels were evident in spleen, thymus, and lymph nodes, and in epithelial organs like the Harderian gland, an intraorbital lachrymal gland found in mice. Very low expression was detected in adult brain, kidney, and skin, tissues with the highest levels of embryonic expression. No expression was detected in heart, liver, or lung. Brca1 mRNA also was expressed in the breast. The pattern of expression in adult tissues is thus similar to that reported for human $B R C A 1$ (Miki et al. 1994)

Because of the association of $B R C A 1$ with human cancers of the breast, we characterized the expression in mammary tissue at several stages of maturation. Interestingly, the steady-state level of Brca1 mRNA expression increased dramatically during pregnancy (Fig. 7A;
Table 2). Expression was elevated $\sim 10$-fold by day 10 of pregnancy and remained high through day 17 (Fig. 7A, lanes 3,4$)$. This increase in expression parallels the wellcharacterized increase in $\alpha$-casein and transferrin $\mathrm{mR}$ NAs, both of which continue to rise as constitutive milk proteins during pregnancy and lactation (Fig. 7A, lanes 3-5). During lactation, steady-state levels of Brca1 mRNA appear to fall (Fig. 7A, lane 5). This apparent decrease is characteristic of genes expressed by mammary cells and can be attributable either to its down-regulation or to dilution resulting for the large accumulation of milk protein mRNAs. During postlactational regression of the mammary gland, Brca1 mRNA levels again increase (lanes 6-8). By day 5 of regression, Brca1 levels appear slightly elevated over those seen in the virgin gland (cf. lanes 2 and 8). Again, it is not clear whether this difference is because of an increase in transcription or an increase in the number of mammary epithelial cells relative to adipocytes in the postlactational versus virgin mammary gland.

To identify cells expressing Brca1 mRNA in the mammary gland and to test whether transcription is downregulated during lactation, we carried out in situ hybridization on sectioned glands at different stages of development. Expression was low but detectable in virgin mammary glands (Fig. 7B). Brca1 transcripts were localized specifically in the mammary epithelial cells, 

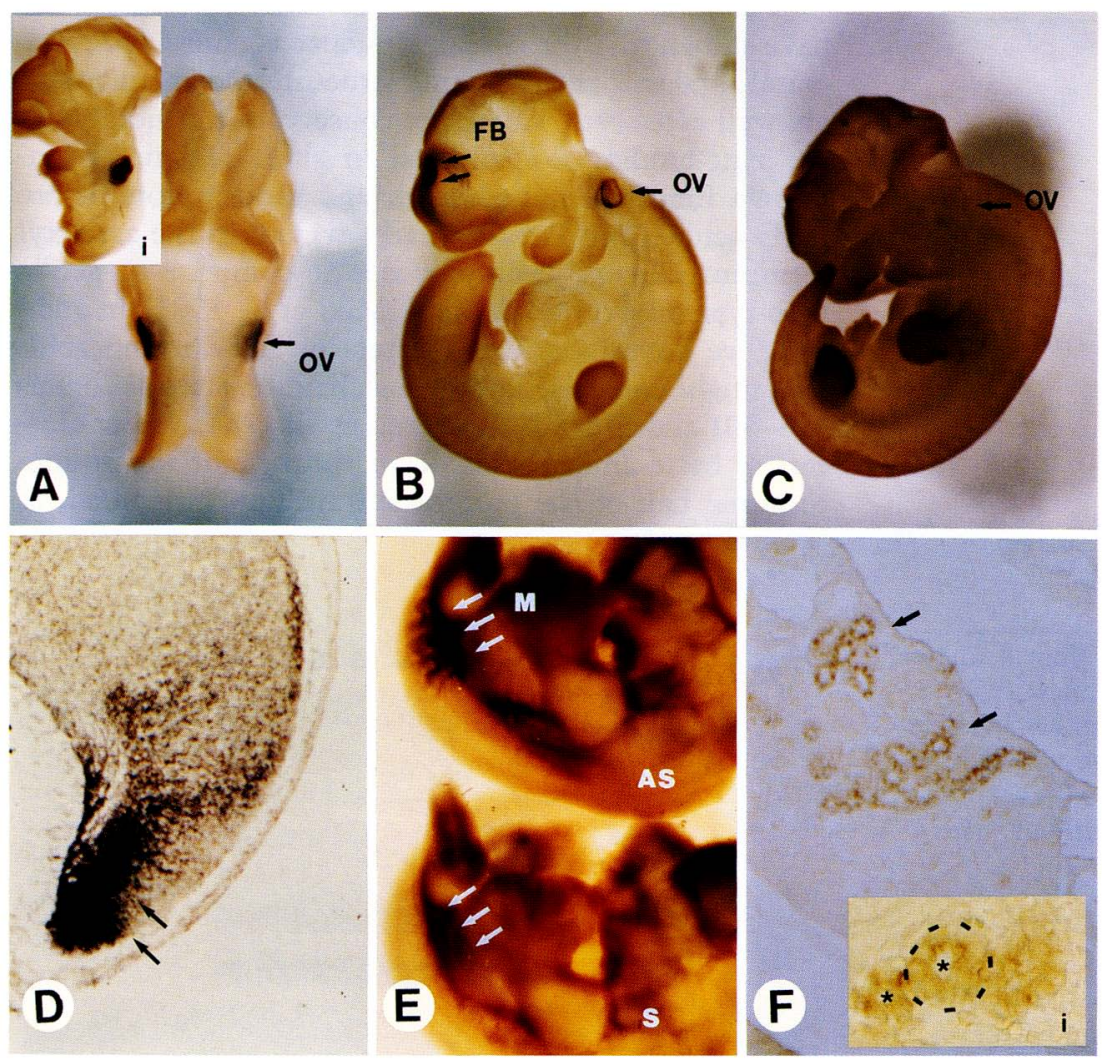

Figure 5. Brca1 is expressed in the embryonic nervous system and kidney. Brca1 mRNA expression was analyzed in mouse embryos by in situ hybridization. (A) Day 9.5 p.c., a dorsal view of a de-epithelialized Swiss-Webster embryo showing positive reaction product in the otic vesicles $(\mathrm{OV})$ hybridized with an antisense Brca1 riboprobe (AS); inset (i), a lateral view of a similar embryo. (B) De-epithelialized E10.5 embryo AS showing diminished otic staining and beginnings of forebrain (FB) staining. (C) Similarly prepared E10.5 control embryo hybridized with a sense riboprobe (S) (D) Section of E11.5 embryo, mesencephalon AS. (E) Day 15.5 embryos, S or AS, arrows identify staining in mesonephros (M) (note high background associated with older embryos). $(F)$ Section of day 17.5 kidney AS; arrows identify nephric tubules. Inset (i), higher magnification of section in $F$. Asterisks identify tubule lumens, and lines identify the basal lamina of one tubule; cytoplasmic Brca1 mRNA is identified by the brown reaction product. Staged mouse embryos were fixed in $4 \%$ paraformaldehyde and prepared for whole mount, or sectioned after imbedding in paraffin. Embryos were stained with antisense or sense riboprobes to the $5^{\prime}$ end of Brca1 (probe B) labeled with D.G.-UTP. Hybridization was detected by an enzymelinked immunoassay that produces a dark brown reaction in positive cells. whereas adipocytes appeared negative. After day 17 of pregnancy, Brca1 mRNA was increased dramatically in both tubular and alveolar epithelial cells but not in the surrounding fat pad (Fig. 7C). Epithelial expression was not elevated appreciably by day 5.5 of pregnancy, a fairly early stage in which epithelial hyperplasia has yet to begin, but was seen by day 13.5 (not shown), consistent with the up-regulation of Brca1 mRNA on RNA blots (Fig. 7A, lane 3). During lactation, Brca1 transcripts were still evident in mammary epithelial cells surrounding ducts and in alveoli. This expression does appear lower than that seen during pregnancy. However, signal inten-
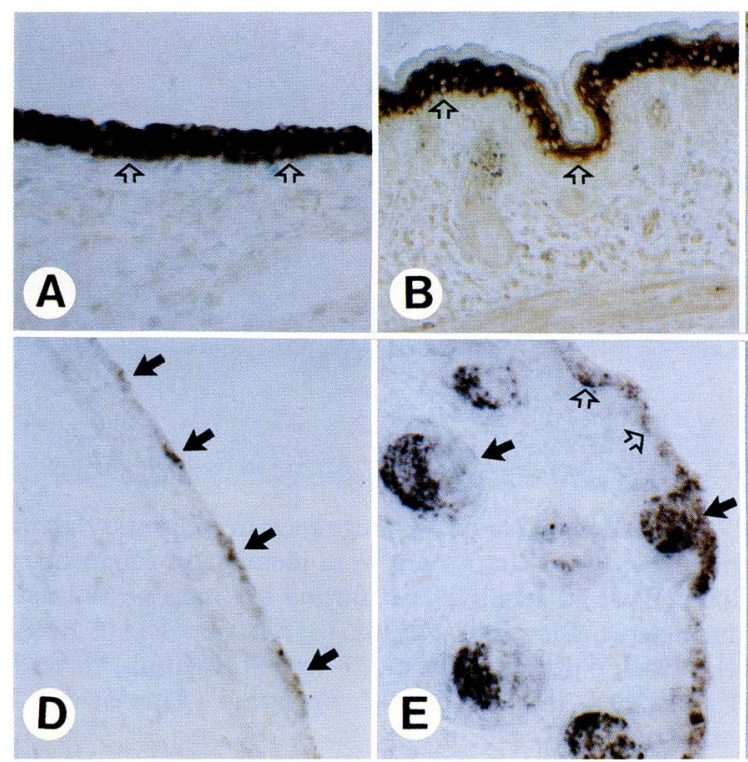

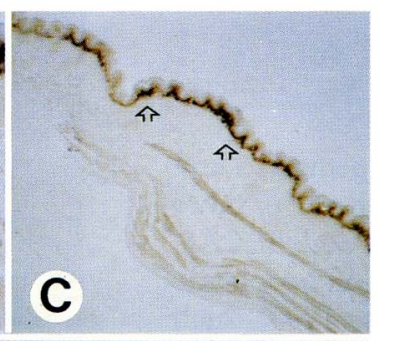

Figure 6. Brca1 is expressed in embryonic skin and whisker pads. Brca1 transcripts were identified by in situ hybridization in sections of embryonic mice. (A) Antisense (AS) Brca1 hybridization to dorsal skin at day 12.5 p.c.; $(B)$ AS of dorsal skin at day $16.5 ;(C)$ AS of ventral skin at day 12.5 . $(D)$ AS of facial skin at day $13.5 ;(E)$ facial skin at day 15.5. Open arrows in $A-C$ and $E$ identify hybridization in basal and suprabasal keratinocytes; solid arrows in $D-F$ identify developing whisker pads. Swiss-Webster embryos were hybridized with antisense $(A, B, D-F)$ or sense $(C)$ riboprobes as described previously (probe B). 
Table 2. Expression of Brcal mRNA in adult tissues

\begin{tabular}{lc}
\hline Tissue & Expression \\
\hline Heart & - \\
Liver & - \\
Lung & - \\
Brain & \pm \\
Kidney & \pm \\
Skin & \pm \\
Thymus & + \\
Axillary lymph node & + \\
Harderian gland & + \\
Testis & + \\
Spleen & ++ \\
Ovary & + \\
Mammary gland & \\
$\quad$ virgin & + \\
$\quad$ day 10 pregnancy & + \\
day 10 lactation & - \\
day 5 regression & +
\end{tabular}

Northern analysis of $2 \mu \mathrm{g}$ of poly $\mid \mathrm{A})^{+}$mRNA from 8 to 10 week-old FVB male mice or 12-week-old female mice. Probe $=$ ${ }^{32} \mathrm{P}$-labeled probe B (Fig. 1). Tissues with a 7.2-kb band visible after 5-day exposure were considered ++ , those with a band after a 14-day exposure were considered + , those with very faint bands at 14 days were considered \pm , tissues without mRNA detected by this method are labeled - .

sity cannot be considered an unbiased measure of RNA molecules per cell. Because considerable hyperplasia occurs during pregnancy and lactation, similar-sized sections show different percentages of a cell's cytoplasm, making direct comparisons of signal intensity hard to interpret. However, it is clear that Brca1 mRNA continues to be present during lactation. We also have found that staining is still present, but much reduced, in ducts after 7 days of regression (not shown). These results indicate that elevated expression of Brca1 is a consequence of pregnancy and might contribute to mammary cell differentiation or withdrawal from the cell cycle during this period.

\section{Discussion}

Genetic analysis of familial breast cancer pedigrees and tumors has suggested that loss of function in one or more growth inhibitory genes ( $p 53, R b, B R C A 1$, and $B R C A 2)$ play causative roles in the development of neoplastic diseases of the breast (Hall et al. 1990; Duffy 1993). Such recessive tumor suppressor alleles might act alone or in concert with dominantly acting oncogenes (such as c-myc and neu/erbB2/HER2) that are often amplified in tumor tissue (Bieche et al. 1994; Tavassoli et al. 1995). Tumor suppressor genes appear to comprise multiple classes but typically act to limit cell-cycle progression or to regulate DNA repair. In addition to their obvious role as antioncogenes, identification of these genes has provided new insights into normal pathways of cellular growth control. In particular, $p 53$ and $R b$ gene products are major regulators of cell-cycle control in mammalian cells and are deleted or mutated in a large percentage of human tumors.

In cloning a mouse homolog of the BRCA1 gene, we have shown that the coding sequence is conserved moderately and that both genomic structure and organization are well conserved. Complete conservation is notable in the zinc-binding domain and in short regions of unknown function. Both human and mouse proteins are fairly acidic. This is particularly evident in the carboxyl terminus that has been proposed to comprise an acidic blob-type interaction domain (Miki et al. 1994). In addition, we have identified clusters of basic amino acids that might comprise nuclear localization sites at codons 495-501 and 598-608 (Kalderon et al. 1984). Other clusters of basic amino acids occur throughout the aminoterminal half of the protein but are not, in general, as
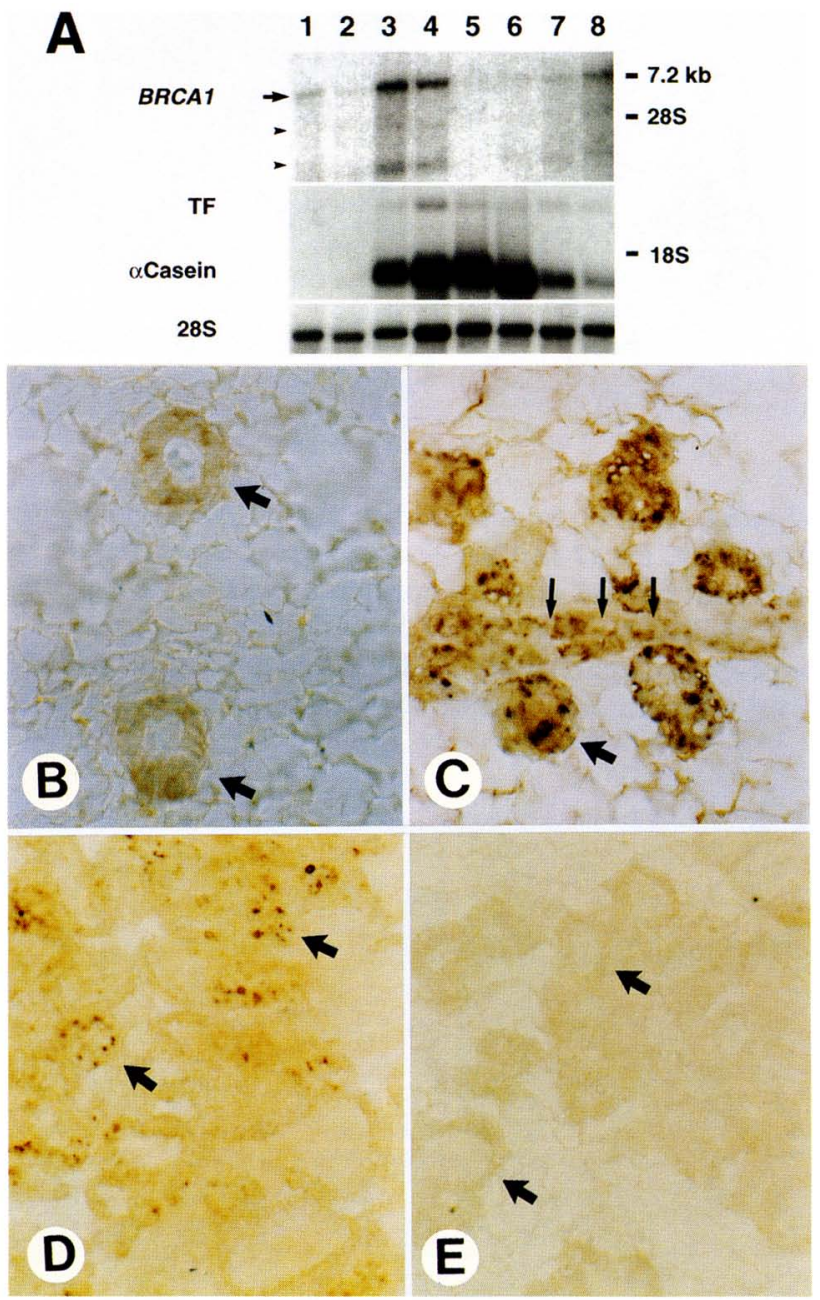

Figure 7. Brca1 is increased by pregnancy in mammary gland epithelial cells. Brca1 transcripts were identified in mammary epithelial cells at all stages of maturation but increase dramatically during pregnancy and lactation. $(A)$ Blot of poly $(A)^{+}$RNA. (Lane 1) 5-week-old virgin; (lane 2) 8-week-old virgin; (lane 3) day 10 pregnancy; (lane 4) day 17 pregnancy; (lane 5) day 2 lactation; (lane 6) 
well conserved. Nuclear localization sites have been observed in other zinc-binding proteins, and their presence in a region encoded by exon 11 might suggest a subcellular targeting function for this unusually large exon (Patarca et al. 1988). Several potential serine phosphorylation sites are conserved between mouse and human sequences. Two of these sites (Ser-582/Ser-586 and Ser$1174 /$ Ser-1178 in the mouse sequence) have the potential for sequential phosphorylation by casein kinase II followed by glycogen synthase kinase 3 (Fiol et al. 1990).

Because of the relatively large size of the Brca1 gene product, the identification of specifically conserved amino acids likely will prove useful in identification of functional domains. In this regard, it is interesting that a number of families with $B R C A 1$-associated pedigrees have mutations that fall within the last 200 amino acids of the coding domain (Futreal et al. 1994; Miki et al. 1994; Merajver et al. 1995). Regions of amino acid identity in this region are relatively short $164 \%$ identity overall), with the longest corresponding to amino acids 16801712 of human BRCA1 and amino acids 1623-1654 of mouse, which are identical in $30 / 32$ amino acids (94\%). The remainder of the carboxyl terminus has smaller stretches of identity but shows considerable conservation in the pattern of hydrophobic and charged residues ( $81 \%$ similarity) that might comprise an interaction domain. Whereas the role of the carboxyl terminus is not clear, the location of several human mutations in this region make functional characterization a priority.

The adult expression pattern of Brca1 is very similar to that described for the human gene (Miki et al. 1994). However, the pattern of expression in embryonic tissues and during mammary development has not been shown previously. We find that Brca1 mRNA is highly expressed during specific stages in the development of a variety of ectodermally derived tissues, including brain, skin, whisker pads, and mammary epithelial cells. In addition, transcripts are seen in mesodermally derived kidney epithelial cells, suggesting additional roles in epithelial differentiation. Brca1 transcripts were also abundant in lymphoid organs, reproductive organs, and cultured fibroblasts, suggesting a more generalized role in these tissues. Because it has been reported that reduced $B R C A 1$ transcription is associated with increased rates of cell proliferation (Thompson et al. 1995), it appears curious that high levels of mRNA expression are associated with so many proliferating cells, both during development and in culture. Particularly intriguing are the elevated levels associated with transformed tissues, especially in mammary tumors and lymphomas. In preliminary experiments, we have detected no rearrangements or gross mutations within Brca1 transcripts in transformed tissues but have noted reduced transcription in one mammary tumor and a novel size class or splice variant in another. Because somatic mutations in the $B R C A 1$ locus appear rare in spontaneous human breast cancers (Futreal et al. 1994), such mutations might also be rare in mouse models of the disease.

Although Brca1 expression in the mammary epithelium was expected from the data on human disease (Hall et al. 1990|, the pregnancy-dependent increase in expression was not predicted. Expression clearly was elevated in mid-pregnancy (day 10) and paralleled the expression of milk protein mRNAs (this study) as well as that reported for c-myc and p53 (Elson et al. 1995). Brca1 expression continued during lactation, as assessed by in situ hybridization, and decreased between 5-7 days after weaning. These results give support to the idea that Brca1 might act as a regulator of cellular maturation or transcription because little proliferation is seen by late pregnancy. It is also unlikely that $B R C A 1$ plays a direct role in apoptosis because its expression is not elevated in glands following weaning, a period of extensive cell death in the mammary gland (Lefebvre et al. 1992).

Differentiation is a common theme in cells that express Brca1. It is interesting that Brca1 is expressed in several epithelial cell types during developmental transitions (day 12 neuroepithelium, keratinocyte differentiation, and mammary epithelial maturation). This association does not appear to hold for transformed cells or for cells in culture, and it remains to be seen how Brca1 function is regulated in these cases. Because Brca1 transcripts were identified in epidermal basal cells of E12.5 embryos, it is clear that Brca1 transcription occurs in proliferating cells in vivo.

Because reductions in Brca1 transcripts have been reported in spontaneous human breast tumors (Thompson et al. 1995), we tested RNAs from a variety of mouse tumors and tumor cell lines for the size and abundance of their Brca1 message. We observed high levels of the 7.2-kD Brca1 mRNA in all cell lines and primary tumors tested and saw few obvious differences between normal and transformed cell lines. Tumor cell lines included those from mammary adenocarcinomas, as well as from dermal fibrosarcomas and two different p53-null lymphoid tumors (Elson et al. 1995). In addition, cell lines derived from fibroblasts (NIH-3T3) displayed high levels of Brca1 mRNA. We note that cell lines expressed 5- to 10-fold more Brca1 than samples from normal tissues. Thus, we found little evidence for loss or rearrangement of Brca1 transcripts in mouse tumors and found that high levels of expression were present in a variety of cells established in culture. As with the $p 53$ tumor suppressor gene, mutations in the coding region of Brca1 might be present in these cells and therefore high levels of mRNA expression might not correlate with functional protein.

We show that Brca1 encodes a zinc finger protein expressed during the differentiation of a variety of epithelial tissues. Genes of this type have been shown to regulate transcriptional control in some systems. Taken together, these results support a model in which Brca1 functions as a regulator of differentiation, a process that often includes transcriptional control and the inhibition of cell-cycle progression. Because we observe Brca1 transcription in proliferating cells in vitro, it is probable that activity of its gene product is regulated in a complex manner, similar to other tumor-suppressor genes, notably the $R b$ gene product (Weintraub et al. 1995). Our observation that Brca1 is elevated during pregnancy is particularly interesting in light of data that the breast 
becomes incrementally more resistant to transformation following pregnancy and lactation (Russo and Russo 1995). Genes like Brca1 thus might function to alter irreversibly cells in which they are expressed, making them less likely to reenter a proliferative state, a function that would be consistent with sites of expression identified in this study. If this is the case, elevated expression of Brca1 mRNA in tumors might indicate an inhibition, or disconnection, of a signaling system that regulates Brca1 activity.

\section{Materials and methods}

\section{Cloning and sequencing}

Oligonucleotides that contain sequence from exon 11 of human BRCA1 (forward primer, 5'-TCATGCCAGCTCATTACAGC; reverse primer $5^{\prime}$-TCCGTTTGGTTAGTTCCCTG) were used to amplify a 752-bp fragment from human DNA by PCR, and the fragment was subcloned into a TA cloning vector (Invitrogen, San Diego, CA). A similar fragment was amplified from mouse DNA with the same primers and subcloned (Fig. 1, probe A). The inserts were sequenced to confirm their identities, and the mouse sequence was used to screen a $129 / \mathrm{Sv}$ J mouse $\lambda$ fixII genomic library (Stratagene, La Jolla, CA). Positive clones were mapped (Fig. 1), and the complete 3317-nucleotide sequence of mouse exon 11 was determined in both directions by a combination of manual dideoxy sequencing (Sequenase, U.S. Biochemical, Cleveland, $\mathrm{OH}$ ) and automated cycle sequencing on an ABI-373A sequencer (Applied Biosystems, Inc., Foster City, CA). Probes from the $5^{\prime}$ and 3 ' ends of exon 11 were then used to screen an E17 embryo $\lambda$ gt 10 cDNA library /Clonetek, Palo Alto, CA). Positive clones were sequenced in both directions using internal primers. Sequences were analyzed with sequence analysis programs from DNASTAR (Madison, WI), the Genetics Computer Group (Madison, WI), and the NCBI Blast server (Altschul et al. 1990).

\section{Genetic mapping}

The mouse Brca1 gene was mapped by analysis of the progeny of the multilocus crosses: (NFS/N or C58/J $\times$ Mus musculus musculus) $\times$ M. m. musculus (Kozak et al. 1990) and (NFS/ $\mathrm{N} \times$ M. spretus $\times \times$ Mus spretus or C58/J (Adamson et al. 1991). Progeny of these crosses have been typed for $>850$ markers, including chromosome 11 markers ecotropic viral integration site 2 (Evi2), small inducible cytokine a2 (Scya2), homeo box 2 cluster $($ Hoxb), avian erythroblastosis oncogene B2 (Erbb2), FK506 binding protein-related protein (Fkbp-rs), wingless-related mouse mammary tumor virus (MMTV) integration site int-4 (Wnt-3), high mobility group 14 related sequence 1 , (Hmg14-1) and protein kinase $\mathrm{C} \alpha(\mathrm{PkCa})$ as described previously (Kozak et al. 1995). The mouse Brca1 cDNA probe (Fig. 1, probe B) identified $B g l$ II fragments of $12.4,3.5$, and $2.8 \mathrm{~kb}$ in parental M. m. musculus DNA, $8.9,3.5$, and 2.8 in NFS/N and C58/J, and 11.8 , and 7.0 in M. spretus. The data were stored and analyzed using the program LOCUS developed by C.E. Buckler [National Institute of Allergy and Infectious Diseases (NIAID), Bethesda, MD]. Recombinational distances and standard errors were calculated according to Green (1981). Genes were ordered by minimizing the number of double recombinants.

\section{Cell lines}

Mammary epithelial cell lines CL-S1 and NMuMG, and NIH3T3 fibroblasts were obtained from the American Type
Culture Collection. Mammary epithelial tumor cell lines HPI-2 and NX1128 were from MMTV-int-2/FGF3 transgenic mice (Muller et al. 1990). AC204, AC236, and AC816 are mammary adenocarcinoma cell lines from $\zeta$-globulin-v-Ha-ras transgenic mice (Leder et al. 1990). AC101 and AC280 are fibrosarcomas, and $\mathrm{ACl} 39$ is a uterine fibrosarcoma from the same line. M158 and $16 \mathrm{MB} 9 \mathrm{a}$ are mammary adenocarcinoma cell lines from MMTV-c-myc transgenic mice (Stewart et al. 1984). NK417 and SMF are mammary adenocarcinoma cell lines from MMTV$n e u / N T$ (erbB2) transgenic mice (Muller et al. 1988). Cell lines were grown to $\sim 85 \%$ confluence in Dulbecco's modified Eagle's medium (DMEM) supplemented with $10 \%$ bovine calf serum, 2 $\mathrm{mM} \mathrm{L}$-glutamine, $100 \mathrm{U} / \mathrm{ml}$ of penicillin, and $100 \mu \mathrm{g} / \mathrm{ml}$ of streptomycin.

\section{Northern blot analysis}

Northern blots were prepared from $2 \mu \mathrm{g}$ of poly $\mid \mathrm{A})^{+}$mRNA isolated from various mouse tissues, and tumor cell lines derived from FVB or Swiss-Webster mice /Chomczynski and Sacchi 1987). Blots were probed with probe $B$, or with probe $B$ in combination with a 4-kb EcoRI fragment corresponding to the 3' end of the Brca1 cDNA (probe C, Fig. 1). Probes were prepared by random-labeling of the insert with $\left[\alpha-{ }^{32} \mathrm{P}\right] \mathrm{CTP}$. Hybridization was carried out in S-buffer for $4-16 \mathrm{hr}$ at $42^{\circ} \mathrm{C}$ [S-buffer $=48 \%$ formamide, $4.8 \times \mathrm{SSC}, 20 \mathrm{~mm}$ Tris- $\mathrm{HCl}$ at $\mathrm{pH} 7.5,10 \%$ dextran sulfate, $1 \times$ Denhardt's solution, $1 \%$ SDS, $20 \mu \mathrm{g} / \mathrm{ml}$ of denatured herring sperm DNA (Sambrook et al. 1989)]. Blots then were washed extensively in $0.1 \% \mathrm{SSC}$ at $60^{\circ} \mathrm{C}$ prior to exposure to autoradiographic film. The amount and quality of RNA present on each blot was assessed by reprobing with a cloned fragment of the 28S rRNA (Rich and Steitz 1987). Quantitation of autoradiographic signals was carried out on a Computing Densitometer equipped with ImageQuant software (Molecular Dynamics, Sunnyvale, CAl.

\section{Tissue preparation and in situ hybridization}

Staged mouse embryos were obtained by natural mating of Swiss-Webster or C57Bl/6 mice. Noon of the day that followed successful mating was considered to be day 0.5 p.c. Gestation was terminated between day 8.5 p.c. and day 18.5 p.c. and embryos were fixed with fresh $4 \%$ paraformaldehyde in phosphatebuffered saline (pH 7.6). Embryos, staged by morphological criteria (Rafferty 1970), were processed for whole-mount in situ hybridization as described (Chan et al. 1995), or were embedded in paraffin, and $5 \mu \mathrm{m}$ sections were mounted on microscope slides prior to in situ hybridization as described by Iruela-Arispe et al. (1993).

Riboprobe templates were generated by linearization of pBSKSII plasmids (Stratagene, La Jolla, CA) that contained a subclone of the 5' $900 \mathrm{bp}$ of Brca1 mRNA (probe B). Riboprobes were synthesized with digoxigenin(DIG)-UTP in in vitro transcription reactions using T3 or T7 RNA polymerase as described by the manufacturer (Boehringer Mannheim, Indianapolis, IN). Hybridization was detected by enzyme-linked immunoassay with an alkaline phosphatase-labeled anti-DIG antisera, and hybrids were visualized with an enzyme-catalyzed color reaction with 5-bromo-4-chloro-3-indolyl phosphate (X-phosphate) and nitroblue tetrazolium salt (NBT) as described by the manufacturer (Boehringer Mannheim).

\section{Acknowledgments}

We thank Dr. Luisa Iruela-Arispe for stimulating discussions and help with in situ hybridizations, Dr. Karen A. Jones for 
reading the manuscript, Ann Kuo for assistance with the library screening, and the Biopolymer Facility, HHMI, Harvard Medical School, for cycle sequencing. T.F.L., C.D., and P.L. were supported by the Howard Hughes Medical Institute. A.E. is the recipient of the Dorot Foundation postdoctoral fellowship.

The publication costs of this article were defrayed in part by payment of page charges. This article must therefore be hereby marked "advertisement" in accordance with 18 USC section 1734 solely to indicate this fact.

\section{References}

Adamson, M.C., J. Silver, and C.A. Kozak. 1991. The mouse homolog of the Gibbon ape leukemia virus receptor: Genetic mapping and a possible receptor function in rodents. Virology 183: 778-781.

Altschul, S.F., W. Gish, W. Miller, E.W. Myers, and D.J. Lipman. 1990. Basic local alignment search tool. I. Mol. Biol. 215: 403-410.

Bieche, I., M.H. Champeme, and R. Lidereau. 1994. A tumor suppressor gene on chromosome 1p32-pter controls the amplification of the myc family genes in breast cancer. Cancer Res. 54: 4274-4276.

Castilla, L.H., F.J. Couch, M.R. Erdos, K.F. Hoskins, K. Calzone, J.E. Garber, J. Boyd, M.B. Lubin, M.L. Deshano, L.C. Brody, F.S. Collins, and B.L. Weber. 1994. Mutations in the BRCA1 gene in families with early-onset breast and ovarian cancer. Nature Genet. 8: 387-391.

Chan, D.C., E. Laufer, C. Tabin, and P. Leder. 1995. Polydactylous limbs in Strong's Luxoid mice result from ectopic polarizing activity. Development 121: 1971-1978.

Chomczynski, P. and N. Sacchi. 1987. Single step method of RNA isolation by acid guanidinium thiocyanate-phenolchloroform extraction. Anal. Biochem. 162: 156-159.

Duffy, M.J. 1993. Cellular oncogenes and suppressor genes as prognostic markers in cancer. Clin. Biochem. 26: 439-47.

Easton, D.F., D.T. Bishop, D. Ford, G.P. Crockford, and B.C.L. Consortium. 1993. Genetic linkage analysis in familial breast and ovarian cancer: Results from 214 families. Am. J. Hum. Genet. 52: 678-701.

Easton, D.F., D. Ford, D.T. Bishop, and B.C.L. Consortium. 1995. Breast and ovarian cancer incidence in $B R C A 1$-mutation carriers. Am. J. Hum. Genet. 56: 265-271.

Elson, A., C. Deng, J. Campos-Torres, L.A. Donehower, and P. Leder. 1995. The MMTV/c-myc transgene and p53 null alleles collaborate to induce T-cell lymphomas, but not mammary carcinomas in transgenic mice. Oncogene 11: 181190.

Fiol, C.J., A. Wang, R.W. Roeske, and P.J. Roach. 1990. Ordered multisite protein phosphorylation: Analysis of glycogen synthase kinase 3 action using model peptide substrates. J. Biol. Chem. 265: 6061-6065.

Freemont, P.S. 1993. The RING finger: A novel protein sequence motif related to the zinc finger. Ann. N.Y. Acad. Sci. 684: 174-192.

Friedman, L.S., E.A. Ostermeyer, C.I. Szabo, P. Dowd, E.D. Lynch, S.E. Rowell, and M.-C. King. 1994. Confirmation of $B R C A 1$ by analysis of germline mutations linked to breast and ovarian cancer in ten families. Nature Genet. 8: 399404.

Futreal, P.A., Q.Y. Liu, D. Shattuck-Eidens, C. Cochran, K. Harshman, S. Tavtigian, L.M. Bennett, A. Haugenstrano, J. Swensen, Y. Miki, K. Eddington, M. Mcclure, C. Frye, J.
Weaverfeldhaus, W. Ding, Z. Gholami, P. Soderkvist, L. Terry, S. Jhanwar, A. Berchuck, J.D. Iglehart, J. Marks, D.G. Ballinger, J.C. Barrett, M.H. Skolnick et al. 1994. BRCA1 mutations in primary breast and ovarian carcinomas. Science 266: 120-122.

Green, E.L. 1981. Lineage, recombination, and mapping. In $\mathrm{Ge}$ netics and probability in animal breeding experiments, pp. 77-112. Oxford University Press, New York.

Hall, J.M., M.K. Lee, B. Newman, J.E. Morrow, L.A. Anderson, B. Huey, and M.C. King. 1990. Linkage of early-onset familial breast cancer to chromosome 17q21. Science 21: 1684 1689.

Haupt, Y., W.S. Alexander, G. Barri, S.P. Klinken, and J.M. Adams. 1991. Novel zinc finger gene implicated as myc collaborator by retrovirally accelerated lymphomagenesis in $\mathrm{E}$ mumyc transgenic mice. Cell 65: 753-763.

Hosking, L., J. Trowsdale, H. Nicolai, E. Solomon, W. Foulkes, G. Stamp, E. Signer, and A. Jeffreys. 1995. A somatic BRCA1 mutation in an ovarian tumour. Nature Genet. 9: 343-344.

Iruela-Arispe, L., D.J. Liska, E.H. Sage, and P. Bornstein. 1993. Differential expression of thrombospondin-1, 2, and 3 transcripts during murine development. Dev. Dyn. 197: 40-56.

Jones, J.S., S. Weber, and L. Prakash. 1988. The Saccharomyces cerevisiae RAD18 gene encodes a protein that contains potential zinc finger domains for nucleic acid binding and a putative nucleotide binding sequence. Nucleic Acids Res. 16: 7119-7131.

Kalderon, D., B.L. Roberts, W.D. Richardson, and A.E. Smith. 1984. A short amino acid sequence able to specify nuclear location. Cell 39: 499-509.

Kozak, C.A., M. Peyser, M. Krall, T.M. Mariano, C.S. Kumar, S. Pestka, and B.A. Mock. 1990. Molecular genetic markers spanning mouse chromosome 10. Genomics 8: 519-524.

Kozak, C.A., M. Danciger, C. Bowes, M.C. Adamson, K. Palczewski, A.S. Polans, and D.B. Farber. 1995. Localization of three genes expressed in retina on mouse chromosome 11 . Mamm. Genome 6: 142-144.

Leder, A., A. Kuo, R.D. Cardiff, E. Sinn, and P. Leder. 1990. $\mathrm{v}$-Ha-ras transgene abrogates the initiation step in mouse skin tumorigenesis: Effects of phorbol esters and retinoic acid. Proc. Natl. Acad. Sci. 87: 9178-9182.

Lefebvre, O., C. Wolf, J.M. Limacher, P. Hutin, C. Wendling, M. LeMeur, P. Basset, and M.C. Rio. 1992. The breast cancerassociated stromelysin- 3 gene is expressed during mouse mammary gland apoptosis. J. Cell Biol. 119: 997-1002.

Litchfield, D.W., A. Arendt, F.J. Lozeman, E.G. Krebs, P.A. Hargrave, and K. Palczewski. 1990. Synthetic phosphopeptides are substrates for casein kinase II. FEBS Lett. 261: 117-120.

Lossie, A.C., M. MacPhee, A.M. Buchberg, and S.A. Camper. 1994. Mouse chromosome 11. Mamm. Genome 5: S164S180.

Lovering, R., I.M. Hanson, K.L.B. Borden, S. Martin, N.J. O'Reilly, G.I. Evan, D. Rahman, D.J.C. Pappin, J. Trowsdale, and P.S. Freemont. 1993. Identification and preliminary characterization of a protein motif related to the zinc finger. Proc. Natl. Acad. Sci. 90: 2112-2116.

Merajver, S.D., T.M. Pham, R.F. Caduff, M. Chen, E.L. Poy, K.A. Cooney, B.L. Weber, F.S. Collins, C. Johnston, and T.S. Frank. 1995. Somatic mutations in the BRCA1 gene in sporadic ovarian tumours. Nature Genet. 9: 439-443.

Miki, Y., J. Swensen, D. Shattuck-Eidens, P.A. Futreal, K. Harshman, S. Tavtigian, Q.Y. Liu, C. Cochran, L.M. Bennett, W. Ding, R. Bell, J. Rosenthal, C. Hussey, T. Tran, M. Mcclure, C. Frye, T. Hattier, R. Phelps, A. Haugenstrano, H. Katcher, K. Yakumo, Z. Gholami, D. Shaffer, S. Stone, S. Bayer, and M.H. Skolnick. 1994. A strong candidate for the 
breast and ovarian cancer susceptibility gene BRCA1. Science 266: 66-71.

Muller, W.J., E. Sinn, P.K. Pattengale, R. Wallace and P. Leder. 1988. Single-step induction of mammary adenocarcinoma in transgenic mice bearing the activated $\mathrm{c}$-neu oncogene. Cell 54: 105-115.

Muller, W.J., F.S. Lee, C. Dickson, G. Peters, P. Pattengale, and P. Leder. 1990. The int- 2 gene product acts as an epithelial growth factor in transgenic mice. EMBO I. 9: 907-913.

Park, I.K., P. Roach, J. Bondor, S.P. Fox, and A.A. DePaoliRoach. 1994. Molecular mechanism of the synergistic phosphorylation of phosphatase inhibitor-2. I. Biol. Chem. 269: 944-954.

Patarca, R., G.J. Freeman, J. Schwartz, R.P. Singh, Q.T. Kong, E. Murphy, Y. Anderson, F.Y. Sheng, P. Singh, K.A. Johnson, S.M. Guarnagia, T. Durfee, F. Blattner, and H. Cantor. 1988. rpt-1, an intracellular protein from helper/inducer $\mathrm{T}$ cells that regulates gene expression of interleukin 2 receptor and human immunodeficiency virus type 1. Proc. Natl. Acad. Sci. 85: 2733-2737.

Rafferty, K.A. 1970. Methods in experimental embryology of the mouse.

Rich, B.E. and J.A. Steitz. 1987. Human acidic ribosomal phosphoproteins P0, P1, and P2: Analysis of cDNA clones, in vitro synthesis, and assembly. Mol. Cell. Biol. 11: 40654074.

Russo, J. and I.H. Russo. 1995. The etiopathogenesis of breast cancer prevention. Cancer Lett. 90: 81-89.

Sambrook, J., E.F. Fritsch, and T. Maniatis. 1989. Molecular cloning, 2nd ed. Cold Spring Harbor Laboratory Press, Cold Spring Harbor, New York.

Stewart, T.A., P.K. Pattengale, and P. Leder. 1984. Spontaneous mammary adenocarcinomas in transgenic mice that carry and express MTV/myc fusion genes. Cell 38: 627-637.

Tagawa, M., T. Sakamoto, K. Shigemoto, H. Matsubara, Y. Tamura, T. Ito, I. Nakamura, A. Okitsu, K. Imai, and M. Taniguchi. 1990. Expression of novel DNA-binding protein with zinc finger structure in various tumor cells. J. Biol. Chem. 265: 20021-20026.

Takahashi, M., Y. Inaguma, H. Hiai, and F. Hirose. 1988. Developmentally regulated expression of a human "finger"containing gene encoded by the 5 ' half of the ret transforming gene. Mol. Cell. Biol. 8: 1853-1856.

Tavassoli, M., M. Alagoz, J. Lee, B.R. Gibson, F. Farzaneh, and N. Kirkham. 1995. Loss of wild type p53 and c-erbB2 amplification correlates with high grade breast carcinomas. Int. $/$. Oncol. 6: 181-186.

Thompson, M.E., R.A. Jensen, P.S. Obermiller, D.L. Page, and J.T. Holt. 1995. Decreased expression of BRCA1 accelerates growth and is often present during sporadic breast cancer progression. Nature Genet. 9: 444-450.

van Lohuizen, M., S. Verbeek, B. Scheihen, E. Weintjens, H. wan der Gulden, and A. Berns. 1991. Identification of cooperating oncogenes in $\mathrm{E}$ mu-myc transgenic mice by provirus tagging. Cell 65: 737-752.

Vassar, R. and E. Fuchs. 1991. Transgenic mice provide new insights into the role of TGF-alpha during epidermal development and differentiation. Genes \& Dev. 5: 714-727.

Weintraub, S.J., K.N. Chow, R.X. Luo, S.H. Zhang, S. He, and D.C. Dean. 1995. Mechanism of active transcriptional repression by the retinoblastoma protein. Nature 375: 812815. 


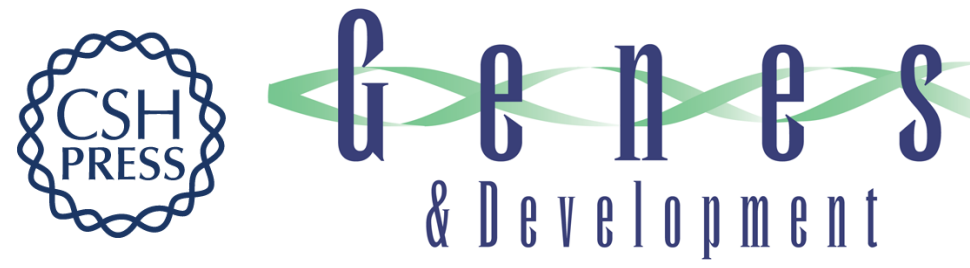

\section{Expression of Brca1 is associated with terminal differentiation of ectodermally and mesodermally derived tissues in mice.}

T F Lane, C Deng, A Elson, et al.

Genes Dev. 1995, 9:

Access the most recent version at doi:10.1101/gad.9.21.2712

References This article cites 43 articles, 13 of which can be accessed free at:

http://genesdev.cshlp.org/content/9/21/2712.full.html\#ref-list-1

License

Email Alerting

Service

Receive free email alerts when new articles cite this article - sign up in the box at the top right corner of the article or click here.

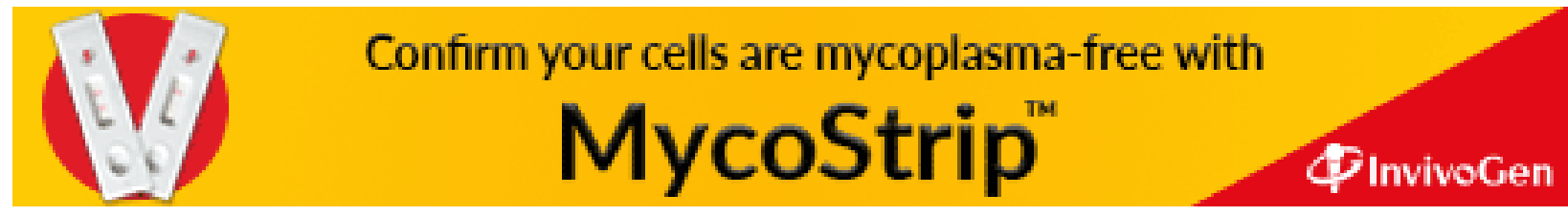

